\title{
DIGESTIBILIDAD DEL CAMOTE Y SU EFECTO SOBRE LA DIGESTIBILIDAD DE CONCENTRADOS USADOS EN LA ALIMENTACIÓN DE PERROS
}

\author{
Lucero Matute G. ${ }^{1}$, Felipe San Martín H. ${ }^{2,3}$, Teresa Arbaiza F. ${ }^{2}$ y Fernando Carcelén C. ${ }^{2}$
}

\section{ABSTRACT}

Five adult dogs maintained in individual cages were used in an experiment under a $5 \times 5$ Latin Square design, to evaluate the in vivo digestibility of the sweet potato, and its effects on the digestibility of commercial dog food. The treatments were $\mathrm{T}_{0}: 100 \%$ concentrated, $\mathrm{T}_{25}: 25 \%$ sweet potato and $75 \%$ concentrated, $\mathrm{T}_{50}: 50 \%$ sweet potato and 50\% concentrated; $\mathrm{T}_{75}: 75 \%$ sweet potato and $25 \%$ concentrated, and $\mathrm{T}_{100}: 100 \%$ sweet potato. Animals were fed at 08:00 hours and feces were previously collected. Proximal analysis of feces and diets were carried out. Each period in the study included 7 days of adaptation and 5 days of control. The digestibility of the dry matter was increased when the sweet potato increased in the ration $(\mathrm{p}<0.05)$. The apparent digestibility of the crude protein and the digestibility of the ethereal extract diminished when the sweet potato levels were increased $(\mathrm{p}<0.05)$. This study showed that the sweet potato has a high digestibility and significantly affects the digestion of nutrients in the dog. An increase of sweet potato increases the digestion of dry matter and energy, but affects the digestibilidad of the crude protein and the ethereal extract.

Key words: sweet potato, digestibility, concentrate

\section{Resumen}

Se evalúo la digestibilidad del camote y su efecto sobre la digestibilidad de alimentos comerciales usados en la alimentación de perros. El diseño experimental fue el cuadrado latino 5x5, para lo cual se empleó cinco perros con edades entre 1.5 a 3 años. Los tratamientos fueron: $\mathrm{T}_{0}: 100 \%$ concentrado, $\mathrm{T}_{25}: 25 \%$ camote y $75 \%$ concentrado, $\mathrm{T}_{50}$ : $50 \%$ camote y $50 \%$ concentrado, $\mathrm{T}_{75}: 75 \%$ camote y $25 \%$ concentrado, y $\mathrm{T}_{100}: 100 \%$ camote. Las dietas fueron ofrecidas a las 08:00 horas previa colección de las heces. Cada periodo del estudio incluyó 7 días de adaptación y 5 días de control. Se realizó el análisis proximal de las dietas y de las heces de cada animal. Los resultados obtenidos indican que la digestibilidad de la materia seca se incrementó cuando se incrementó el camote en la ración $(\mathrm{p}<0.05)$. La digestibilidad aparente de la proteína cruda y la digestibilidad del extracto etéreo disminuyeron $(\mathrm{p}<0.05)$ cuando se incrementaron los niveles de camote. El estudio demostró que el camote posee una alta digestibilidad y afecta significativamente la digestión de nutrientes en el perro. Un incremento de camote aumenta la digestión de la materia seca y de la energía, pero afecta la digestibilidad de la proteína cruda y del extracto etéreo.

Palabras clave: camote, digestibilidad, concentrado

\footnotetext{
${ }^{1}$ Práctica privada

${ }^{2}$ Laboratorio de Bioquímica, Nutrición y Alimentación Animal, FMV-UNMSM

${ }^{3}$ E-mail: decanovet@unmsm.edu.pe
} 


\section{INTRODUCCIÓN}

El perro es un mamífero que pertenece a la familia de los carnívoros, pero debido a su convivencia con el hombre se ha adaptado a una dieta mucho más variada que la proporcionada únicamente por las presas animales. Existe en la actualidad una gran variedad de alimentos comerciales disponibles para perros en cada etapa de su vida y estado fisiológico. Estos alimentos comerciales normalmente cubren los requerimientos nutritivos del perro para que lleve una vida saludable (Case et al., 1997).

En los últimos años se ha incrementado el uso de alimentos concentrados comerciales para perros en el Perú; sin embargo, dadas las condiciones socioeconómicas en la cual se encuentra el país, un gran sector de la población de dueños de mascotas los siguen alimentando con dietas caseras y en otros casos reemplazan parcialmente las dietas caseras con los concentrados. El alimento casero ocasiona en algunos casos desórdenes digestivos perjudiciales para las mascotas.

El camote ha sido y es utilizado con frecuencia como un alimento completo en la alimentación de caninos, debido a su aceptabilidad y precio, pero sin tomar en cuenta su valor nutritivo, especialmente, el bajo contenido proteico y graso. Los carbohidratos constituyen una fuente rápida y valiosa de energía. Su consumo en exceso es transformado en grasa por lo que perros alimentados, únicamente, con camote tienden a ser animales obesos. Además, su consumo crónico, como único componente de la dieta de perros, puede conllevar a deficiencia proteica, y por lo tanto, puede acarrear retraso del crecimiento en los animales jóvenes por pérdida de peso y deterioro del rendimiento reproductivo y de trabajo (Case et al., 1991). Asimismo el consumo de dietas pobres en proteína da lugar a una disminución de los niveles plasmáticos de proteínas y puede, en última instancia, provocar edema o ascitis.
No existe información concreta y fehaciente sobre el verdadero aprovechamiento digestivo del camote en el perro y sobre su influencia en el aprovechamiento de otros nutrientes. Es así, que este estudio se realizó con el objetivo de evaluar la digestibilidad del camote en perros y su influencia sobre la digestivilidad de dietas comerciales preparadas para perros.

\section{Matmbriales y Métodoos}

Se utilizó cinco (5) perros machos cruzados, adultos, de tamaño mediano, con un peso aproximado de $20 \mathrm{~kg}$, pelo corto, y con edades que fluctuaron entre 1.5 a 3 años. Los animales provenían del Centro Antirrá-bico de la Ciudad de Lima.

Los animales recibieron un alimento balanceado comercial (concentrado) para perros adultos, al que se le añadió camote cocinado en las siguientes proporciones:

$\mathrm{T}_{0}: 100 \%$ concentrado - $0 \%$ camote $\mathrm{T}_{25}: 75 \%$ concentrado $-25 \%$ camote $\mathrm{T}_{50}: 50 \%$ concentrado $-50 \%$ camote T75: $25 \%$ concentrado - $75 \%$ camote $\mathrm{T}_{100}: 0 \%$ concentrado $-100 \%$ camote

Los animales se mantuvieron alojados en caniles individuales ( $0.94 \mathrm{~m}$ de ancho, 1.95 $\mathrm{m}$ de alto, $2.0 \mathrm{~m}$ de profundidad). El análisis de los alimentos y heces se realizó en el Laboratorio de Bioquímica, Nutrición y Alimentación Animal de la Facultad de Medicina Veterinaria de la Universidad Nacional Mayor de San Marcos.

Los animales pasaron por una etapa de observación de 15 días, tiempo durante el cual se observó el estado de salud y conducta, recibiendo sólo alimento balanceado. Luego de este periodo se realizó una evaluación general sobre la condición clínica mediante análisis de sangre, orina y heces (examen parasitológico), y se les aplicó un tratamiento antiparasitario. Se les aplicó además, una vacuna sextuple recibiendo un refuerzo a los 30 
días. Los animales fueron sometidos a ejercicios moderados por un tiempo aproximado de 15 minutos y luego recibieron la única alimentación del día (entre las 08:00 y 09:00). El agua fue ofrecida ad libitum. Las heces se recolectaron momentos antes de ofrecer el alimento (Fig. 1)

La fase experimental estuvo compuesta por un periodo de acondicionamiento con una duración de 7 días para cada tratamiento, y por un periodo de control de 5 días, durante el cual se registró el consumo individual por día.

Se realizó el análisis químico proximal de las dietas experimentales y de las muestras de heces para la estimación de la digestibilidad aparente.

Se utilizó el Cuadrado Latino 5x5 como diseño experimental donde las columnas fueron los 5 animales y las filas fueron los tratamientos por los cuales pasaron en forma aleatoria cada uno de los 5 animales. Se usó la prueba de diferencia de medias significativas de Fisher protegida para determinar las diferencias entre los tratamientos.

\section{Resultados y Discusión}

Los resultados del análisis proximal del camote cocinado se presentan en el Cuadro 1 ,
Cuadro 1. Análisis químico proximal del camote $^{1}$

\begin{tabular}{lc}
\hline Componente & $\begin{array}{c}\% \text { en } \\
\text { base seca }\end{array}$ \\
\hline Proteína cruda & 3.0 \\
Extracto etéreo & 0.7 \\
Fibra cruda & 2.9 \\
Cenizas & 1.6 \\
Extracto libre de nitrógeno & 91.8 \\
\hline
\end{tabular}

${ }^{1}$ Humedad: $76.5 \%$

y son similares a los obtenidos por Luh y Momaw (1979) y Ayahuano (1987).

El camote es un alimento energético debido al alto contenido de carbohidratos (91.8\% de extracto libre de nitrógeno). El principal carbohidrato del camote es el almidón, nutriente altamente digestible, sobre todo si se le somete a cocción. El almidón se descompone químicamente con el calor liberando maltosa, dextrina y otros azúcares, que junto con pequeñas cantidades de sacarosa contribuyen a dar el sabor dulce a este producto.

La digestibilidad in vivo de los nutrientes por tratamientos se muestra en el Cuadro 2. La digestibilidad de la materia seca (DMS) fue menor $(\mathrm{p}>0.05)$ para el $\mathrm{T}_{0}$ comparado

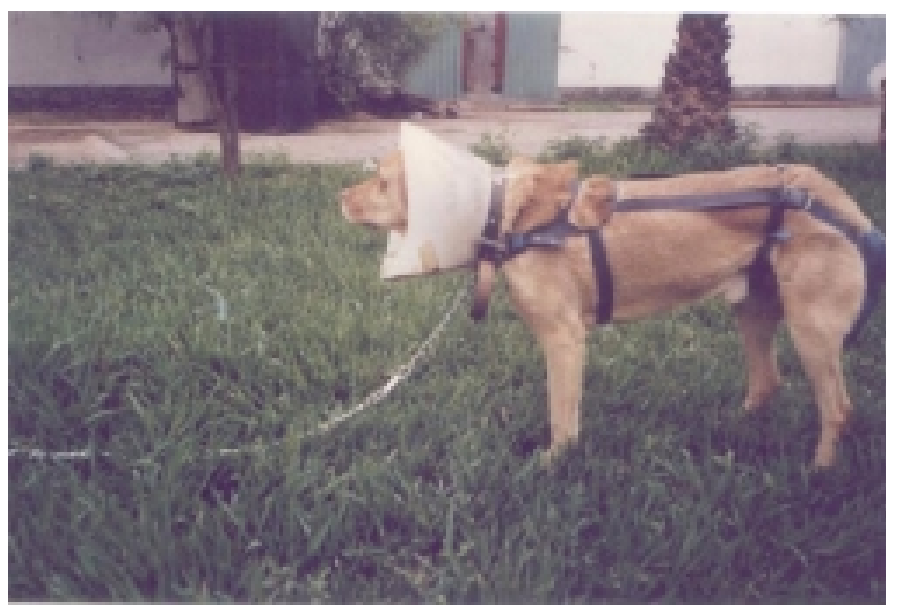

Figura 1. Perro mostrando el equipo de recolección de heces 
Cuadro 2. Digestibilidad aparente de la materia seca y extracto libre de nitrógeno por tratamiento

\begin{tabular}{ccccccc}
\hline \multirow{2}{*}{ Tratamientos $^{1}$} & \multicolumn{2}{c}{ Digestibilidad de la materia seca } & & \multicolumn{2}{c}{ Extracto libre de nitrógeno } \\
\cline { 2 - 3 } \cline { 5 - 6 } \cline { 5 - 6 } \cline { 5 - 6 } T0 & Promedio & d.e. ${ }^{2}$ & & Promedio & d.e \\
T25 & $73.6^{\mathrm{c}}$ & 1.3 & & $78.0^{\mathrm{c}}$ & 3.7 \\
T50 & $87.2^{\mathrm{b}}$ & 3.4 & & $89.5^{\mathrm{b}}$ & 2.6 \\
T75 & $88.5^{\mathrm{ab}}$ & 1.3 & & $91.9^{\mathrm{ab}}$ & 1.9 \\
T100 & $92.1^{\mathrm{a}}$ & 2.3 & & $94.3^{\mathrm{a}}$ & 2.1 \\
\hline
\end{tabular}

${ }^{1} \mathrm{~T}_{0}: 100 \%$ concentrado; $\mathrm{T}_{25}: 75 \%$ concentrado y $25 \%$ camote; $\mathrm{T}_{50}: 50 \%$ concentrado y $50 \%$ camote;

$\mathrm{T}_{75}: 25 \%$ concentrado y $75 \%$ camote; $\mathrm{T}_{100}: 100 \%$ camote

${ }^{2}$ d.e. = desviación estándar

abc Letras diferentes dentro de columnas indican diferencia estadística significativa $(p<0.05)$

Cuadro 3. Digestibilidad aparente de la proteína cruda y extracto etéreo por tratamientos

\begin{tabular}{cccccc}
\hline \multirow{2}{*}{ Tratamientos $^{1}$} & \multicolumn{2}{c}{ Proteína } & & \multicolumn{2}{c}{ Extracto etéreo } \\
\cline { 2 - 3 } \cline { 5 - 6 } \cline { 5 - 6 } \cline { 5 - 6 } T0 & Promedio & d. $\mathrm{e}^{2}$ & & Promedio & d.e. \\
T25 & $77.2^{\mathrm{b}}$ & 2.8 & & $92.1^{\mathrm{a}}$ & 1.1 \\
T50 & $89.5^{\mathrm{a}}$ & 3.9 & & $96.1^{\mathrm{a}}$ & 0.9 \\
T75 & $87.9^{\mathrm{a}}$ & 2.3 & & $96.1^{\mathrm{a}}$ & 0.9 \\
T100 & $89.9^{\mathrm{a}}$ & 2.7 & & $96.0^{\mathrm{a}}$ & 2.0 \\
\hline
\end{tabular}

\footnotetext{
${ }^{1} \mathrm{~T}_{0}: 100 \%$ concentrado; $\mathrm{T}_{25}: 75 \%$ concentrado y $25 \%$ camote; $\mathrm{T}_{50}: 50 \%$ concentrado y $50 \%$ camote;

$\mathrm{T}_{75}: 25 \%$ concentrado y $75 \%$ camote; $\mathrm{T}_{100}: 100 \%$ camote

${ }^{2}$ d.e.= desviación estándar

abc Letras diferentes dentro de columnas indican diferencias estadísticas significativas $(p<0.05)$
}

con los otros tratamientos. No hubo diferencias entre los tratamientos con inclusión de camote ( $\mathrm{p}>0.05)$. Estos resultados concuerdan con lo encontrado por Silvio et al. (2000), quienes encontraron valores de digestibilidad superiores por la adición de pectina (fibra altamente fermentable). Estos autores indicaron, además, que si bien la DMS se incre- menta con la adición de carbohidratos fermentables, en la ración se afecta la digestibilidad de la proteína (DPC).

El camote tiene una alta digestibilidad en vacunos (Goyzueta, 1963) y cerdos (Angulo et al., 1979), y se usa en la alimentación de estas especies como fuente energética en 
reemplazo del maíz. La digestibilidad del camote se mejora por el proceso de cocción, como ha sido demostrado en perros y gatos (Ramsos et al., 1976; Trudell y Morris, 1975).

La DPC (Cuadro 3), es superior en $\mathrm{T}_{25}$, $\mathrm{T}_{50}, \mathrm{~T}_{75}$ comparado con $\mathrm{T}_{0}(\mathrm{p}<0.05)$; sin embargo, la DPC quedó muy comprometida bajando al $17.3 \%$ en el $\mathrm{T}_{100}(100 \%$ de camote). Se ha demostrado que la DPC disminuye cuando la cantidad de carbohidratos en la ración se aumenta, ya que promueven la actividad bacteriana a nivel intestinal, aumentando la excreción de proteína microbiana por las heces (Silvio et al., 2000).

La DPC y DMS en la dieta libre de camote $\left(\mathrm{T}_{0}\right)$ fueron inferiores a los señalados por Capia (2000), quien da valores de $80 \mathrm{y}$ $82 \%$ para DMS y DPS versus 74 y $77 \%$ obtenidos en este estudio. Asimismo, inferiores a lo señalado por Kendall et al. (1982) que indica que los alimentos comerciales poseen digestibilidades de 81,85 y $79 \%$ para la proteína, grasa y ELN, respectivamente.

La digestibilidad del extracto etéreo (DEE) fue inferior en el $\mathrm{T}_{0}$ con respecto a los demás $(\mathrm{p}<0.05)$. Este resultado se explica por un lado, por el bajo contenido de EE en el camote $(0.67 \%)$ y por otro lado, debido a que el contenido graso en alimentos comerciales es alto y de buena calidad.

\section{Conclusiones}

- La digestibilidad de la materia seca del alimento comercial evaluado en el perro se incrementa a medida que se incluye camote en la ración.

- La digestibilidad de la materia seca del camote es superior al $80 \%$, pero la digestibilidad del componente proteico y del extracto etéreo son muy bajos (17 y $24 \%$, respectivamente), por lo que no se recomienda como alimento único en la dieta de caninos.

\section{Literatura Citada}

1. Angulo, M.; W. López; H. Brinke. 1979. Yuca, camote y grano de soya en engorde de cerdos. Memoria Asociación Latinoamericana de Producción Animal. V Reunión 14: 64.

2. Ayahuano, S. 1987. Estudio químico bromatológico de tres variedades de Ipomoea batata. Tesis Lic. en Química. UNSA. Arequipa, Perú. 85 p.

3. Case, L.; D. Carey; D. Hirakawa. 1997. Nutrición canina y felina. Manual para profesionales. p 95, 141, 350, 351352. España.

4. Capia, M. 2000. Efecto de la inclusión de soluble de pescado en dietas comerciales, sobre la recuperación de la condición corporal de perros adultos. Tesis Médico Veterinario. Fac. Medicina Veterinaria, Universidad Nacional Mayor de San Marcos, Lima, Perú.

5. Goyzueta, M. 1963. Camote fresco en el engorde de bovinos de carne. Tesis Bachiller. Fac. Medicina Veterinaria, Univ. Nacional Mayor de San Marcos Lima, Perú.

6. Kendall, P.T; D.W. Holme; P.M. Smith. 1982. Methods of prediction of the digestible energy content of dog foods from gross energy value, proximate analisys and digestible nutrient content. J. Sci. Food. Ag. 3: 823-828.

7. Luh, C.L; J.C. Moomaw. 1979. Present role and future outlook for sweet potato in Asia research and development needs. Manila, Philipines. $5^{\text {th }}$ Int. Symp. Trop. Rest. Crops. p 1-30.

8. Ramsos, D.R.; P.S. Belo; M.R. Bennink. 1976. Effects of dietary carbohidrate, fat and protein on growth, body composition and blood metabolite levels in the dog. J. Nutr. 106: 1452-1464.

9. Silvio, J.; D.L. Horman; K. Gross; K. Mclead. 2000. Influencia de la capacidad de fermentación de la fibra sobre la digestión de nutrientes en el perro. Nutrition 16: 289- 295.

10. Trudell, J.I.; J.G. Morris. 1975. Carbohydrate digestion in the cat. J. Anim. Sci. 41: 329. 